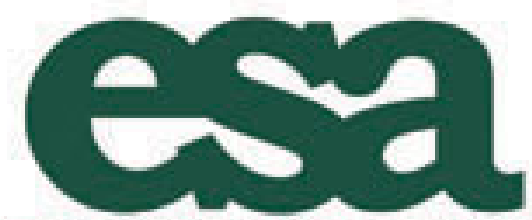

Promoting the Science of Ecology

Mothers Matter: Crowding Leads to Stressed Mothers and Smaller Offspring in Marine Fish Author(s): Mark I. McCormick

Source: Ecology, Vol. 87, No. 5 (May, 2006), pp. 1104-1109

Published by: Ecological Society of America

Stable URL: http://www.jstor.org/stable/20069049

Accessed: 23/11/2009 18:33

Your use of the JSTOR archive indicates your acceptance of JSTOR's Terms and Conditions of Use, available at http://www.jstor.org/page/info/about/policies/terms.jsp. JSTOR's Terms and Conditions of Use provides, in part, that unless you have obtained prior permission, you may not download an entire issue of a journal or multiple copies of articles, and you may use content in the JSTOR archive only for your personal, non-commercial use.

Please contact the publisher regarding any further use of this work. Publisher contact information may be obtained at http://www.jstor.org/action/showPublisher?publisherCode=esa.

Each copy of any part of a JSTOR transmission must contain the same copyright notice that appears on the screen or printed page of such transmission.

JSTOR is a not-for-profit service that helps scholars, researchers, and students discover, use, and build upon a wide range of content in a trusted digital archive. We use information technology and tools to increase productivity and facilitate new forms of scholarship. For more information about JSTOR, please contact support@jstor.org. 


\title{
REPORTS
}

Ecology, 87(5), 2006, pp. 1104-1109

(c) 2006 by the Ecological Society of America

\section{MOTHERS MATTER: CROWDING LEADS TO STRESSED MOTHERS AND SMALLER OFFSPRING IN MARINE FISH}

\author{
MARK I. MCCORMICK ${ }^{1}$ \\ School of Marine Biology and Aquaculture, James Cook University, Townsville, Queensland 4811 Australia
}

Abstract. Most marine populations are sustained by the entry of juveniles that have survived the larval phase, during which time most die. The number of survivors depends strongly on the quality of the eggs produced by spawning females, but it is not known how the social conditions under which breeding occurs influence the quality of larvae produced. Here I show that the density of females interacting with breeding mothers directly influences the size of larvae produced, through a stress-related mechanism. On the Great Barrier Reef of Australia, breeding pairs of a damselfish, Pomacentrus amboinensis, were isolated on habitat patches, and additional females that could not access the spawning site were added at four densities $(0,1,3$, or 6 females). Additional females increased aggressive interactions by mothers and increased the levels of the stress hormone, cortisol, in their ovaries, leading to reduced larval size. Neither egg output nor yolk size of the larvae was influenced by female density. Pairs breeding in isolation produced the largest larvae; current theory suggests that these larvae should contribute most to subsequent population replenishment events. This social mechanism may influence which females effectively contribute to the next generation and may promote resilience in patchy or isolated populations.

Key words: Allee effects; damselfish; density dependence; Great Barrier Reef, Australia; larval size; maternal effects; offspring quality; Pomacentrus amboinensis; silver-spoon effect; social interactions; stress.

\section{INTRODUCTION}

The question of what influences the replenishment of marine populations is fundamental to our understanding of population dynamics (Doherty 2002), fisheries management (Dower et al. 2000), and conservation (Jones et al. 2004). Most marine populations are sustained by the successful entry of juveniles that have survived high levels of mortality during the larval phase (Houde 1987). The number of survivors depends not only on the number of eggs produced by the mothers, but also on the quality of those eggs. Recent studies show that mortality during the early life history of fish is selective, and can be traced back to the characteristics of the larvae at hatching (Bergenius et al. 2002, Vigliola and Meekan 2002). Larval fish that grow fast, and are larger for a given age, have higher survival as larvae (Bergenius et al. 2002, Wilson and Meekan 2002) and as settled juveniles (Searcy and Sponaugle 2001, Hoey and McCormick 2004, McCormick and Hoey 2004). Studies on a range of terrestrial and aquatic taxa have shown

Manuscript received 12 July 2005; revised 16 December 2005; accepted 23 December 2005. Corresponding Editor: M. A. Hixon.

${ }^{1}$ E-mail: mark.mccormick@jcu.edu.au that there are genetic and nongenetic influences on initial offspring characteristics (Chambers and Leggett 1996, Heath and Blouw 1998, Wade 1998, Berkeley et al. 2004, Green and McCormick 2005, Trippel et al. 2005) that affect survival in later ontogenetic stages (Pechenik et al. 1998, Marshall et al. 2003).

Nongenetic maternal effects have recently been found to underpin the "silver spoon effect" (Grafen 1988) in a number of terrestrial taxa, where the early life history characteristics of an individual have a disproportionate effect on its later survival and reproductive success (Madsen and Shine 2000, Hofer and East 2003). This effect may generate substantial variation in life history characteristics, such as growth and developmental rate. Given that size is highly correlated with swimming performance in teleost fishes (Bailey and Houde 1989, Stobutzki 1998, Fisher et al. 2000, Clark et al. 2005), and is related to survival through enhanced acquisition of food and predator avoidance (e.g., Sogard 1997), this maternally induced variation may generate much of the spatial and temporal diversity in survival. Unfortunately, for most marine organisms we have little understanding of the factors that generate nongenetic variation in life history traits. 
In the present study I experimentally test whether nongenetic maternal influences on offspring characteristics are density dependent in the coral reef fish, Pomacentrus amboinensis (Pomacentridae). I also explore the physiological mechanism underlying these maternal effects. Findings illustrate how social interactions in one generation may strongly influence the developmental characteristics of the next.

\section{MethodS \\ Study species}

The focal species for this study was the damselfish, Pomacentrus amboinensis, a common member of the demersal fish community in the tropical Indo-Pacific. This protogynous reef fish lives in social groups consisting of one male, which guards a benthic nest site, and 1-7 females (Jones 1987; M. I. McCormick, unpublished data). The females have a strong dominance hierarchy, and the largest, most dominant female has primary access to the nest site (M. I. McCormick, unpublished data).

\section{Experimental protocol}

Males and females were collected with hand-nets from the continuous shallow reef around Lizard Island $\left(14^{\circ} 41^{\prime} \mathrm{S}, 145^{\circ} 27^{\prime} \mathrm{E}\right)$ on the northern Great Barrier Reef, Australia, and were randomly placed in reproductive pairs onto 39 rubble lagoonal patch reefs $(1.5 \times$ $1.5 \mathrm{~m}$ ), isolated from each other and the main reef by at least $15 \mathrm{~m}$ of sand in 3-4 m water depth. A plastic half tile (30 cm long, $18 \mathrm{~cm}$ diameter) was placed on each reef, and was readily used by the male as a nesting surface. One of four different densities of additional females was then randomly assigned to the breeding pairs: no additional female; one female; three females; and six females. Although nine or 10 replicates of each treatment were conducted over a three-month period, $6-$ 7 replicate breeding pairs in each treatment successfully bred by the end of the experiment. The added females were confined in 3-L clear plastic jars with mesh bottoms and these jars were wired to the patch reef to provide a conspecific stimulus, but prohibit access to the nest site (see Plate 1). These added fish were fed every third day and were replaced every $\sim 10$ days to minimize the negative effects on the confined fish. Female mean size did not differ among experimental treatments or from the adjacent reef population (range of standard length $53.1-68.1 \mathrm{~mm} ; F_{4,23}=0.122, P=0.973$ ).

\section{Parental behavior}

Behavioral budgets were determined for all breeding females and males on patch reefs and for dominant females and nest-guarding males in social groups on the nearby continuous reef. Behavioral observations were made between 1030 and 1430 hours over a 5-day period, with observations of replicate fish within each treatment spread approximately evenly over the census period (511 replicate fish were assessed per treatment and sex).

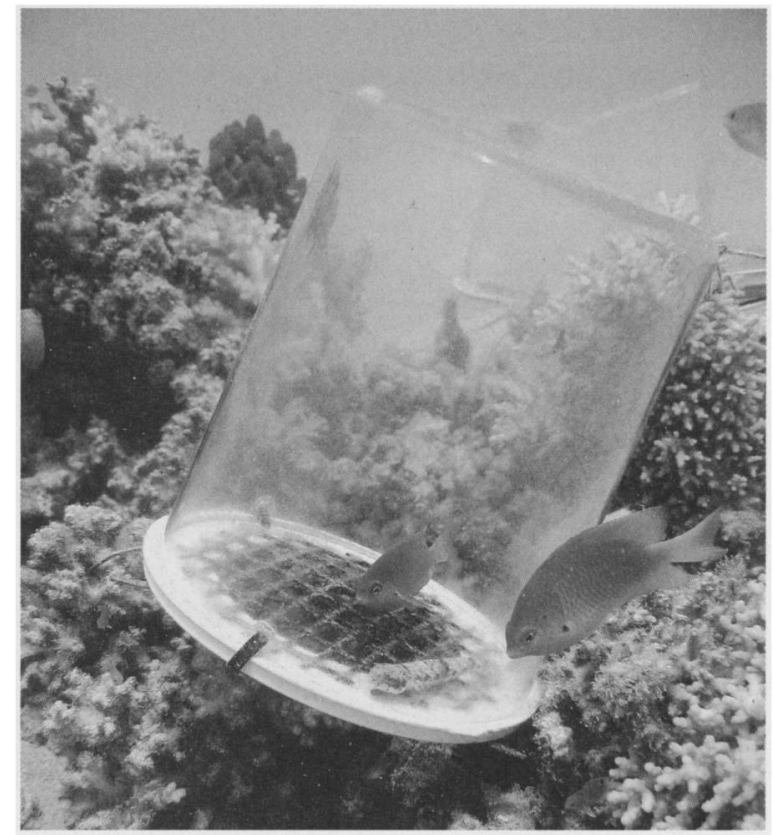

Plate 1. A Pomacentrus amboinensis female interacts with one of the confined females on an experimental patch reef. Photo credit: M. McCormick.

Behavior occurrence was recorded in categories every 15 $\mathrm{s}$ over a 10 -min focal sampling period. Behaviors were categorized as: displaying (showing side to target and erecting dorsal and anal fins); circling (swimming close, stopping frequently and looking at the target fish); chasing; biting; undirected swimming; feeding; and courting. Target species of interactions were also recorded. Total aggressive interactions were quantified as the sum of the first four behavioral categories. Mean levels of aggression were compared among treatments using one-way ANOVA $\left(\log _{10}(x+1)\right.$-transformed, Type III sums of squares), after a residual analysis of the assumptions of normality and homogeneity of variance. A Tukey's hsd means comparison was used to examine the nature of the significant difference found by ANOVA.

\section{Clutch size and larval morphology}

Clutches were photographed in situ, with a transparent $1-\mathrm{cm}^{2}$ grid positioned on top for a scale, on the morning of spawning. Optimus 6.5 computer image analysis (Media Cybernetics 1999) was used to estimate the area of clutches from the digital images. The mean density of eggs was estimated from counts in three randomly chosen $1-\mathrm{cm}$ grid squares. Clutch area and density were used to estimate the number of eggs produced in a $30-d$ period for each breeding female. Clutches were brought into the laboratory just prior to hatching ( $4.5 \mathrm{~d}$ after being spawned). Hatching occurred naturally in aquaria $\sim 15-20 \mathrm{~min}$ after sunset. Larvae were immediately collected with a small net, preserved in $2.5 \%$ glutaraldehyde in seawater for 2 hours at room 


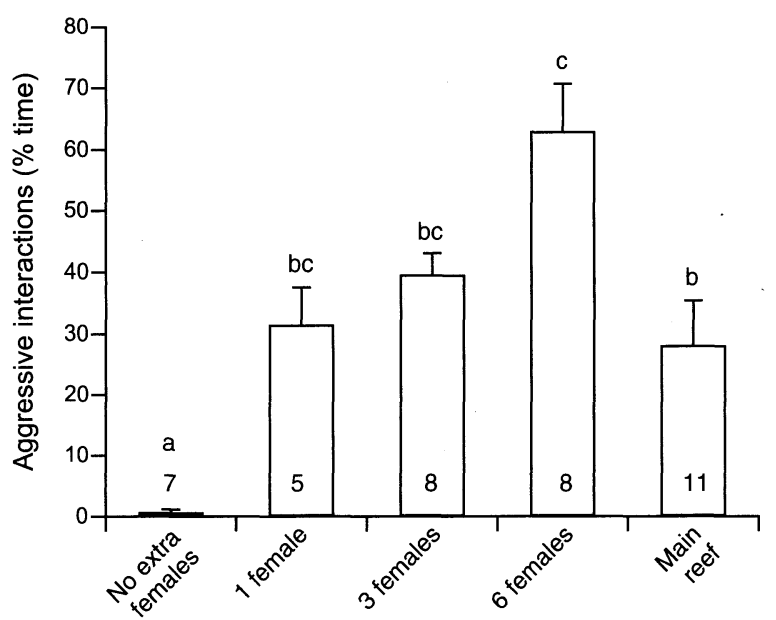

FIG. 1. Percentage of time spent in aggressive behavior (mean $+\mathrm{SE}$ ) by dominant female Pomacentrus amboinensis in breeding pairs on isolated patch reefs when exposed to a varying number of additional captive females. Aggression by females from the main reef is also given for comparison. Sample sizes (number of females) are given in each bar, and letters above the bars represent Tukey's hsd groupings of means.

temperature, rinsed in seawater, then transferred to fresh seawater and refrigerated for morphometric analyses. Standard length (SL), oil globule, and yolk sac twodimensional area (lateral view) of 30 larvae from each nest were measured from calibrated digital images taken of each larva through a binocular microscope with the aid of image analysis software (Optimus 6.5). Yolk sac and oil globule area provided a measure of the endogenous reserves available for subsequent development. Mean larval morphology per breeding female was used as the replicate level for analyses. Mean larval morphology and number of eggs produced (in a 30-d period) were compared among treatments with ANOVA. Tukey's hsd means comparison tests were used to examine the nature of the significant difference found by ANOVA.

\section{Cortisol assays}

Radioimmunoassays were undertaken to determine maternal levels of the stress-associated hormone, cortisol (Gorbman et al. 1983). Females from all the treatments were sampled using a fence net, after larvae from their second clutch of eggs had been collected. For comparison, 20 females were collected at the end of the experiment from the population on the adjacent main reef. All females were killed by cold shock, measured (SL) and weighed. Their ovaries were then removed, weighed, and frozen at $-20^{\circ} \mathrm{C}$ before being processed (within three months of collection). Ovary tissue $(\sim 0.1 \mathrm{~g}$ wet mass) was freeze-dried and homogenized in $200 \mu \mathrm{L}$ $0.05 \mathrm{~mol} / \mathrm{L}$ phosphate buffer containing $0.1 \%$ gelatine and $0.01 \%$ thimerosal (Sigma Chemical Company, St. Louis, Missouri, USA). We added $1 \mathrm{~mL}$ of ethyl acetate, and then vortexed and centrifuged the sample. Duplicate $100-\mu \mathrm{L}$ aliquots were evaporated in assay tubes. Cortisol in ovary extracts was assayed according to the protocol of Pankhurst and Carragher (1992). The radioactive tracer used was $\left(1,2,6,7-{ }^{3} \mathrm{H}\right)$ cortisol (TRK407; Amersham, Little Chalfont, Buckinghamshire, UK) and the antiserum was developed against cortisol-3-carboxymethyloxime-bovine serum albumin in rabbits (UCBA907/R1Y; Accurate Chemical and Scientific Corporation, Westbury, New York, USA). This antiserum is reported to have cross reactivities to corticosterone $(1.8 \%)$ and aldosterone $(<0.02 \%)$. Interassay variability for cortisol was $\mathrm{Cv}=8.3 \%$ ( $n=6$ replicates). Mean ovarian cortisol (ng/g ovary mass processed) was compared among treatments with ANOVA. A Tukey's hsd means comparison was used to examine the nature of the significant difference found by ANOVA.

\section{Results AND Discussion}

Ten-minute behavioral observations one month after the establishment of the density treatments showed that the addition of females significantly elevated the levels of aggression of the breeding female $\left(F_{4,34}=31.441, P<\right.$ 0.0001; Appendix, Table A1; Fig. 1). Breeding females on control reefs with no additional females displayed the lowest levels of aggression, whereas those in the sixfemale treatment displayed the highest. Importantly, the range over which aggression was elevated by the manipulations was within the naturally occurring range found for dominant females on the main reef, which ranged between $0 \%$ and $85.4 \%$ of the total time budget. Male aggression was lower than that of females, with treatment means ranging from $4.7 \%$ to $14.0 \%$ of the total time budget, but did not differ among treatments $\left(F_{4,31}=2.437, P=0.068\right.$; Appendix, Table A2). Results suggest that the female density treatments had little influence on the male activity levels, but had a densitydependent influence on the activity of the breeding female.

There was a negative relationship between the number of experimentally added females and the standard length of the larvae produced by the breeding females $\left(F_{4,26}=31.610, P<0.0001\right.$; Appendix, Table A3; Fig. 2). Females on control reefs with no added females produced the largest larvae, which were, on average, $8.8 \%$ larger than larvae from the treatment with six additional females and $9 \%$ larger than larvae produced from nests on the main reef. The mean size of larvae produced by these control treatment females was larger than the maximum size of larvae from egg clutches sampled from breeding fish on the main reef ( 2.78 vs. $2.71 \mathrm{~mm} \mathrm{SL}$ ). The size range across all female density treatments represented $17.1 \%$ of the mean larval size at hatching. This figure is very similar to our best estimate of the size range of larvae produced by this species from all habitats around Lizard Island: $17.0 \%$ of the mean larval size. This estimate of natural variability in larval size was obtained from larvae from 50 nests 


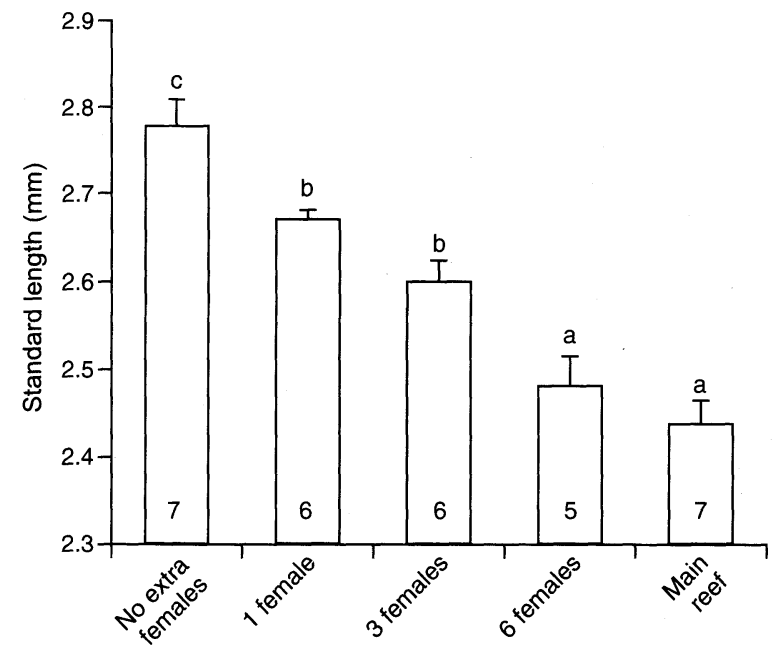

FIG. 2. Standard length of larvae at hatching (mean + SE) from dominant female Pomacentrus amboinensis in breeding pairs on isolated patch reefs when exposed to a varying number of additional captive females. Lengths of larvae produced by females from the main reef are also given for comparison. Sample sizes (number of larvae) are given in each bar, and letters above the bars represent Tukey's hsd groupings of means.

located from diverse habitats around Lizard Island (McCormick 1999). The similarity of the treatmentinduced size range $(17.0 \%)$ to the natural size range $(17.1 \%)$ of larvae suggests that social interactions, operating through maternal influences, may indeed account for much of the variability found in larval size at hatching in the natural system. These maternal influences may therefore be an important source of variability influencing the quality of larvae available for population replenishment.

Treatments did not influence either the yolk sac size of the larvae at hatching or the numbers of eggs produced by breeding females $\left(F_{4,26}=0.192, P=0.940 ; F_{3,17}=\right.$ $1.098, P=0.377$, respectively; Appendix, Tables A4 and A5). Previous studies of teleosts suggest that stress influences egg or larval size (Campbell et al. 1992, 1994, McCormick 1998, 1999), whereas nutritional supplementation, whether natural or artificial, influences the size of endogenous yolk reserves of the larvae at hatching (Kerrigan 1997, McCormick 2003).

Levels of the stress-associated hormone, cortisol, were significantly lower in breeding females on patch reefs with no additional females, and cortisol in the breeding females increased directly with the number of additional females on reefs $\left(F_{4.50}=5.524, P=0.0009\right.$; Appendix, Table A6; Fig. 3). This result indicates that female ovarian cortisol levels were density dependent. Other studies have found a link between conspecific density, the number of social interactions, and cortisol, but these studies typically have densities well beyond natural levels, such as in the case of intensive aquaculture (Barnett and Pankhurst 1998, Barcellosa et al. 2004) or habitat bottlenecks (Boorse and Denver 2003). In the present study, cortisol levels of the high-density treatment (mean $122.6 \mathrm{ng} / \mathrm{g}$ ) were well within the range of cortisol levels found in dominant females sampled from the main reef (17-172 $\mathrm{ng} / \mathrm{g}$ ), suggesting that experimental manipulations were within natural limits and may conservatively estimate the impact of density-dependent stress on the main reef population.

There was a negative relationship between mean ovarian cortisol per treatment and the standard length of larvae at hatching that accounted for $87 \%$ of the variation in larval length $\left(r^{2}=0.87, P=0.069, n=4\right.$ treatments). This pattern supports a correlative study of the same species that found a similar, although weaker $\left(r^{2}=0.48, P<0.001\right)$, negative relationship between ovarian cortisol of dominant females and larval standard length, based on 50 monitored nest sites from five locations around the Lizard Island continuous reef (McCormick 1998). Furthermore, the same study found a strong relationship between maternal ovarian cortisol and levels of cortisol in the eggs once spawned. Correlative evidence has been supported by field and laboratory experiments showing that elevated maternal cortisol directly resulted in smaller larvae (McCormick 1998, 1999). Cortisol directly influences embryological rhythms, such that higher levels of cortisol speed up all developmental rhythms, but do not accelerate development itself (McCormick and Nechaev 2002). Thus, available evidence suggests that maternal cortisol is elevated by density-dependent mechanisms that operate directly through a socially mediated, stress-related mechanism.

Interestingly, dominant females on the main reef had a relatively low occurrence of aggressive interactions and low mean cortisol levels, but the larvae collected from

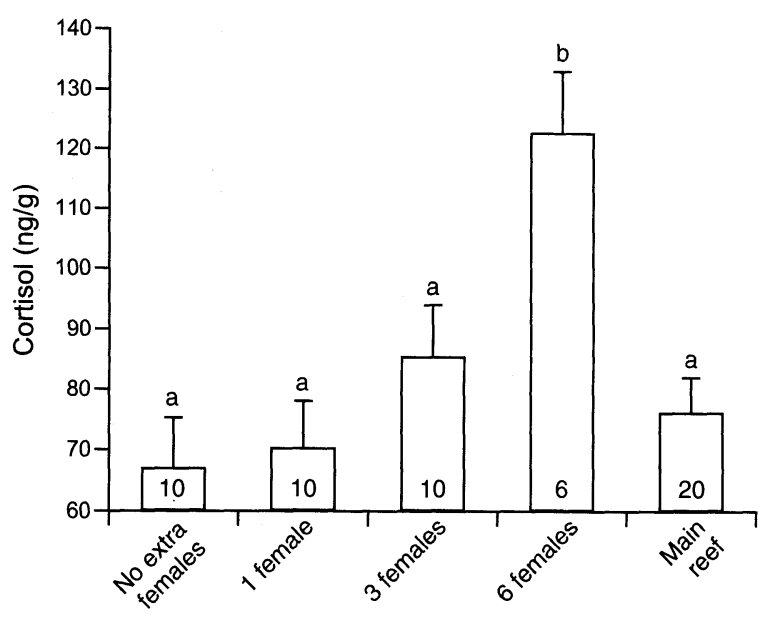

FIG. 3. Ovarian cortisol levels (mean $+\mathrm{SE}$ ) of dominant female Pomacentrus amboinensis in breeding pairs on isolated patch reefs when exposed to a varying number of additional captive females. Cortisol levels of females from the main reef are also given for comparison. Sample sizes (number of females) are given in each bar, and letters above the bars represent Tukey's hsd groupings of means. 
reef spawning sites had the smallest standard lengths. Information on visitations into male nest sites by this fish species suggest that the dominant female is not the only female to contribute to egg clutches held by the male (McCormick and Smith 2004). Indeed, females can only spawn a maximum of every second day (M. I. McCormick, unpublished data), while eggs are found or nests on the main reef during the spawning season every day. It is likely that subordinate fish, which have higher cortisol levels (M. I. McCormick, unpublished data), contribute to these nests, thereby lowering the mean larval size. Further studies are required to determine the relative importance to progeny quality of social status of the spawning females and the density at which they live.

This is the first study to show that density-dependent stress affects the quality of larvae of a marine organism. Females at low densities had the lowest cortisol levels and produced the largest larvae. A previous study founc that breeding female Pomacentrus amboinensis on isolated habitat patches away from conspecific interactions had the lowest ovarian cortisol levels of fish in any reef habitat (McCormick 1998). The implication of these findings for the resilience of the population is that, when population densities are low and patchily distributed, such as at the limits of geographic ranges, maternal conditions will promote the production of large larvae that may have a higher probability of surviving (Leggett and DeBlois 1994, Berkeley et al. 2004). This effect may help to ameliorate Allee effects, or inverse density dependence at low population densities (Courchamp et al. 1999, Stephens et al. 1999, Gascoigne and Lipcius 2004). Depensatory Allee effects can result in critical population size or density thresholds, below which the population crashes to extinction. There is need for further studies that address how the stress-related control of larval size influences the individuals that survive the larval phase to settle. If future studies find that females in low density, under conditions of low stress, contribute disproportionately to the next generation, then the density-dependent control of larval size may be important for population resilience.

\section{ACKNOWLEDGMENTS}

I thank S. Smith and C. Berkström for assistance in the field and P. Munday, J. Jones, G. Almany, M. Hixon, S. Sponaugle, and an anonymous reviewer for comments on the manuscript. This study was funded through an Australian Research Council Centre of Excellence. Research was conducted under the James Cook University animal ethics guidelines.

\section{Literature Cited}

Bailey, K. M., and E. D. Houde. 1989. Predation on eggs and larvae of marine fishes and the recruitment problem. Advances in Marine Biology 26:1-83.

Barcellosa, L. J. G., L. C. Kreutza, R. M. Quevedob, I. Fiorezec, L. Cericatod, A. B. Sosod, M. Fagundesd, J. Conradd, R. K. Baldisserad, A. Bruschid, and F. Ritterd. 2004. Nursery rearing of jundia, Rhamdia quelen (Quoy, and Gaimard) in cages: cage type, stocking density and stres: response to confinement. Aquaculture 232:383-394.
Barnett, C., and N. Pankhurst. 1998. The effects of common laboratory and husbandry practices on the stress response of greenback flounder Rhombosolea tapirina (Gunther, 1862). Aquaculture 162:313-329.

Bergenius, M. A. J., M. G. Meekan, D. R. Robertson, and M. I. McCormick. 2002. Larval growth predicts the recruitment success of a coral reef fish. Oecologia 131:521-525.

Berkeley, S. A., C. Chapman, and S. M. Sogard. 2004. Maternal age as a determinant of larval growth and survival in a marine fish, Sebastes melanops. Ecology 85:1258-1264.

Boorse, G. C., and R. J. Denver. 2003. Endocrine mechanisms underlying plasticity in metamorphic timing in spadefoot toads. Integrative and Comparative Biology 43:646-657.

Campbell, P. M., T. G. Pottinger, and J. P. Sumpter. 1992. Stress reduces the quality of gametes produced by rainbow trout. Biology of Reproduction 47:1140-1150.

Campbell, P. M., T. G. Pottinger, and J. P. Sumpter. 1994. Preliminary evidence that chronic confinement stress reduces the quality of gametes produced by brown and rainbow trout. Aquaculture 120:151-169.

Chambers, R. C, and W. C. Leggett. 1996. Maternal influences on variation in egg sizes in temperate marine fishes. American Zoologist 36:180-196.

Clark, D. L., J. M. Leis, A. C. Hay, and T. Trnski. 2005. Swimming ontogeny of larvae of four temperate marine fishes. Marine Ecology Progress Series 292:287-300.

Courchamp, F., T. H. Clutton-Brock, and B. Grenfell. 1999. Inverse density dependence and the Allee effect. Trends in Ecology and Evolution 14:405-410.

Doherty, P. J. 2002. Variable replenishment and the dynamics of reef fish populations. Pages 327-355 in P. F. Sale, editor. Coral reef fishes: dynamics and diversity in a complex ecosystem. Academic Press, San Diego, California, USA.

Dower, J., W. C. Leggett, and K. T. Frank. 2000. Improving fisheries oceanography in the future. Pages 263-281 in P. Harrison and T. R. Parsons, editors. Fisheries oceanography: an integrative approach to fisheries ecology and management. Blackwell Science, Oxford, UK.

Fisher, R., D. R. Bellwood, and S. D. Job. 2000. The development of swimming abilities in reef fish larvae. Marine Ecology Progress Series 202:163-173.

Gascoigne, J., and R. N. Lipcius. 2004. Allee effects in marine systems. Marine Ecology Progress Series 269:49-59.

Gorbman, A., W. W. Dickhoff, S. R. Vigna, N. B. Clark, and C. L. Ralph. 1983. Comparative endocrinology. John Wiley, New York, New York, USA.

Grafen, A. 1988. On the uses of data on lifetime reproductive success. Pages 454-471 in T. H. Clutton-Brock, editor. Reproductive success. Studies of individual variation in contrasting breeding systems. University of Chicago Press, Chicago, Illinois, USA.

Green, B. S., and M. I. McCormick. 2005. Maternal and paternal influences determine size, growth and performance in a tropical reef fish larvae. Marine Ecology Progress Series 289:263-272.

Heath, D. D., and D. M. Blouw. 1998. Are maternal effects in fish adaptive or merely physiological side effects? Pages 178 201 in T. A. Mouseau and C. W. Fox, editors. Maternal effects as adaptations. Oxford University Press, New York, New York, USA.

$\rightarrow$ Hoey, A. S., and M. I. McCormick. 2004. Selective predation for low body condition at the larval-juvenile transition of a coral reef fish. Oecologia 139:23-29.

Hofer, H., and M. L. East. 2003. Behavioral processes and costs of co-existence in female spotted hyenas: a life history perspective. Evolutionary Ecology 17:315-331.

Houde, E. D. 1987. Fish early life dynamics and recruitment variability. American Fisheries Society Symposium 2:17-29.

Jones, G. P. 1987. Competitive interactions among adults and juveniles in a coral reef fish. Ecology 68:1534-1547. 
$\rightarrow$ Jones, G. P., M. I. McCormick, M. Srinivasan, and J. V. Eagle 2004. Coral decline threatens fish biodiversity in marine reserves. Proceedings of the National Academy. of Sciences (USA) 101:8251-8253.

Kerrigan, B. A. 1997. Variability in larval development of a tropical reef fish (Pomacentridae: Pomacentrus amboinensis): the parental legacy. Marine Biology 127:395-402.

Leggett, W. C., and E. DeBlois. 1994. Recruitment in marinifishes: Is it regulated by starvation and predation in the egg and larval stages? Netherlands Journal of Sea Research 32: 119-134.

$\rightarrow$ Madsen, T., and R. Shine. 2000. Silver spoons and snake body sizes: prey availability early in life influences long-term growth rates of free-ranging pythons. Journal of Animal Ecology 69:952-958.

$\rightarrow$ Marshall, D. J., T. F. Bolton, and M. J. Keough. 2003. Offspring size affects the post-metamorphic performance of $\mathrm{c}-$ colonial marine invertebrate. Ecology 84:3131-3137.

$\rightarrow$ McCormick, M. I. 1998. Behaviorally induced maternal stress in a fish influences progeny quality by a hormonal mechanism. Ecology 79:1873-1883.

McCormick, M. I. 1999. Experimental test of the effect of maternal hormones on larval quality of a coral reef fish. Oecologia 118:412-422.

$\rightarrow$ McCormick, M. I. 2003. Consumption of coral propagules after mass spawning enhances larval quality of a damselfish through maternal effects. Oecologia 136:37-45.

$\rightarrow$ McCormick, M. I., and A. S. Hoey. 2004. Larval growth history determines juvenile growth and survival in a tropical marine fish. Oikos 106:225-242.

McCormick, M. I., and I. V. Nechaev. 2002. Influence of cortisol on developmental rhythms during embryogenesis in a tropical damselfish. Journal of Experimental Zoology 293: 456-466.

McCormick, M. I., and S. A. Smith. 2004. Efficacy of passive integrated transponder tags to determine spawning site visitations by a tropical fish. Coral Reefs 23:570-577.
Media Cybernetics. 1999. Optimus 6.5. Media Cybernetics, Silver Spring, Maryland, USA.

Pankhurst, N. W., and J. F. Carragher. 1992. Oocyte maturation and changes in plasma steroid levels in snapper Pagrus (=Chrysophrys) auratus (Sparidae) following treatment with human chorionic gonadotropin. Aquaculture 101: 337-347.

Pechenik, J. A., D. E. Wendt, and J. N. Jarrett. 1998. Metamorphosis is not a new beginning. Larval experience influences juvenile performance. BioScience 48:901-910.

$\rightarrow$ Searcy, S. P., and S. Sponaugle. 2001. Selective mortality during the larval-juvenile transition in two coral reef fishes. Ecology 82:2452-2470

Sogard, S. M. 1997. Size-selective mortality in the juvenile stage of teleost fishes: a review. Bulletin of Marine Science 60: 1129-1157.

Stephens, P. A., W. J. Sutherland, and R. P. Freckleton. 1999. What is the Allee effect? Oikos 87:185-190.

Stobutzki, I. C. 1998. Interspecific variation in sustained swimming ability of late pelagic stage reef fish from two families (Pomacentridae and Chaetodontidae). Coral Reefs 17:111-120.

Trippel, E. A., G. Kraus, and F. W. Köster. 2005. Maternal and paternal influences on early life history traits and processes of Baltic cod Gadus morhua. Marine Ecology Progress Series 303:259-267.

Vigliola, L., and M. G. Meekan. 2002. Size at hatching and planktonic growth determine post-settlement survivorship of a coral reef fish. Oecologia 131:89-93.

Wade, M. J. 1998. The evolutionary genetics of maternal effects. Pages 5-21 in T. A. Mousseau and C. W. Fox, editors. Maternal effects as adaptations. Oxford University Press, New York, New York, USA.

Wilson, D. T., and M. G. Meekan. 2002. Growth-related advantages for survival to the point of replenishment in the coral reef fish Stegastes partitus (Pomacentridae). Marine Ecology Progress Series 231:247-260.

\section{APPENDIX}

Results of statistical analyses (Ecological Archives E087-062-A1). 